\title{
O/W Nanoemulsion as an Adjuvant for an Inactivated H3N2 Influenza Vaccine: Based on Particle Properties and Mode of Carrying
}

This article was published in the following Dove Press journal: International Journal of Nanomedicine

\author{
Lanhua Zhao $\mathbb{D}^{1,2}$ \\ Zhe Zhu' \\ Lei Ma' \\ Yingbo $\mathrm{Li}^{1}$
}

'Institute of Medical Biology, Chinese Academy of Medical Sciences, Peking Union Medical College, Kunming 650II8, People's Republic of China; ${ }^{2}$ Institute of Pathogenic Biology, School of Medicine, University of South China, Hengyang, 42100I, People's Republic of China
Correspondence: Yingbo Li

Tel +86 I3888034695

Email lyb@imbcams.com
Background and Purpose: Adjuvant can reduce vaccine dosage and acquire better immune protection to the body, which helps to deal with the frequent outbreaks of influenza. Nanoemulsion adjuvants have been proved efficient, but the relationship between their key properties and the controlled release which greatly affects immune response is still unclear. The present work explores the role of factors such as particle size, the polydispersity index (PDI), stability and the safety of nanoemulsions by optimizing the water concentration, oil phase and modes of carrying, to explain the impact of those key factors above on adjuvant effect.

Methods: Isopropyl myristate (IPM), white oil, soybean oil, and grape-kernel oil were chosen as the oil phase to explore their roles in emulsion characteristics and the adjuvant effect. ICR mice were immunized with an emulsion-inactivated H3N2 split influenza vaccine mixture, to compare the nanoemulsion's adjuvant with traditional aluminium hydroxide or complete Freund's adjuvant.

Results: Particle size of all the nanoemulsion formed in our experiment ranged from $20 \mathrm{~nm}$ to $200 \mathrm{~nm}$ and did not change much when diluted with water, while the PDI decreased obviously, indicating that the particles tended to become more dispersive. Formulas with $80 \%$ or $85.6 \%$ water concentration showed significant higher HAI titer than aluminium hydroxide or complete Freund's adjuvant, and adsorption rather than capsule mode showed higher antigen delivery efficiency. As mentioned about oil phase, G (IPM), F (white oil), $\mathrm{H}$ (soybean oil), and I (grape-kernel oil) showed a decreasing trend in their adjuvant efficiency, and nanoemulsion $\mathrm{G}$ was the best adjuvant with smaller and uniform particle size. Conclusion: Emulsions with a smaller, uniform particle size had a better adjuvant effect, and the adsorption mode was generally more efficient than the capsule mode. The potential adjuvant order of the different oils was as follows: IPM > white oil > soybean oil > grape-kernel oil.

Keywords: nanoemulsion, influenza vaccine, particle properties, mode of carrying, oil phase

\section{Introduction}

Influenza is an acute respiratory infection disease around the globe. The US Centers for Disease Control and Prevention (CDC) estimates that seasonal influenza is responsible for an average of more than 20,000 deaths annually. ${ }^{1}$ Mortality is highest in infants and the elderly. The 2012-2013 influenza season was notable for widespread disease and a higher death rate than those reported in previous years. In addition, the predominant influenza virus subtype was $\mathrm{H} 3 \mathrm{~N} 2$, in contrast to dominance by H1N1 subtypes in recent years. ${ }^{2}$ 
Vaccination remains the primary cost-effective method for the prevention and control of influenza. Among healthy young adults, vaccination can prevent $70-90 \%$ of influenza-specific illness. Nevertheless, administration of the usual dose of influenza vaccine can provide only limited protection for persons aged 65 years, due to age-related degeneration of the immunologic system. ${ }^{3}$

Adjuvants play an important role in enhancing the immunogenicity of vaccines. ${ }^{4}$ Nanoemulsion is a kind of steady system that is usually composed of an emulsifier, co-emulsifier, oil phase and aqueous phase. As a vaccine adjuvant, this system is efficient, and many nanoemulsions have been proven safe. Humenza ${ }^{\circledR}$, an Influenza H1N1 vaccine from Sanofi Pasteurand, which combined with a new $\mathrm{O} / \mathrm{W}$ type emulsion AF03, was approved by EMACHMP. $^{5,6}$ Also, the MF59 adjuvanted subunit influenza vaccine (Fluad) provides an improved immune response for those aged 65 years and older. ${ }^{7}$ In addition, nanoemulsion adjuvant such as MF59 and AS03 have been proven to enhance the adaptive response by activating the innate immune system locally and increasing antigen uptake and presentation in draining lymph nodes. ${ }^{8-10}$ However, Pandemrix which contains AS03 has been associated with an increased risk of narcolepsy in adolescent recipients in the $2009 \mathrm{H} 1 \mathrm{~N} 1$ pandemic. ${ }^{11}$ A possible mechanism underlying the association of the H1N1 adjuvant vaccine with narcolepsy might be molecular mimicry involving cross-reactivity of H1N1-specific T cells and hypocretinproducing neurons, ${ }^{12}$ predicting the potential risk of AS03; therefore, a growing need has arisen for new adjuvants with improved safety. Currently, there are still many nanoemulsion adjuvants under basic research on animals only, and some are in preclinical stage.

As a vaccine adjuvant, nanoemulsions present advantages such as antigen protection. ${ }^{13}$ Increasing the surface area of an antigen, which is favourable for antigen presentation, slow release of the antigen, ${ }^{14}$ uniform dispersion and good stability. However, the relationship between its physicochemical properties and the immune response mechanism is not clear, ${ }^{15}$ further research on safety, and formula optimization should be considered. ${ }^{16}$

Particle size, the polydispersity index (PDI) and carrying mode are considered to be key factors that influence the nanoemulsion adjuvant effect. ${ }^{17-19}$ Additionally, the aqueous phase and oil phase play an important role in nanoemulsion formation. ${ }^{20-22}$ In our research, different NEs are mixed with an $\mathrm{H} 3 \mathrm{~N} 2$ vaccine, and their adjuvant effects in a mouse model are considered, to explore how these parameters change the immune response intensity, aiming to choose the best formulation for further application.

\section{Materials and Methods Materials}

Cremophor EL was purchased from Acros (Belgium). Tween 80 and Tween20 were purchased from Shanghai Sangon Biological (Shanghai, China). Span80 was purchased from the Tianjin Guangfu Chemical Industry Institute (Tianjin, China). 1,2-Propylene glycol was purchased from Xilong Chemical Co. LTD (Guangzhou, China). 7\# white oil was obtained from Taizhou Mingxin Petrochemical LTD (Taizhou, China). Grapeseed oil was procured from Wuhan Hezhong Biochemical Production (Wuhan, China). Complete Freund's adjuvant and soybean oil was purchased from Sigma-Aldrich (St. Louis, MO). Isopropyl myristate (IPM) was purchased from Tokyo Chemical Co.LTD (Tokyo, Japan). Aluminium hydroxide was provided by Institute of Medical Biology, Chinese Academy of Medical Science (Kumming, China). Female ICR mice (Qualified number: SCXK (Yunnan), 20100003), which was certificated by the Ethics Committee of Peking Union Medical College, and the inactivated split influenza vaccine (B/Brisbane/60/2008 virus) were provided by the Institute of Medical Biology, Chinese Academy of Medical Science (Kumming, China). H3N2 Influenza strain (2009NYMC, X-187Victoria) was provided by Chinese CDC (Beijing, China), Dialysis membranes (MD44 8000-14000D, Solarbio, Beijing, China), ELISA kits were obtained from Yaanda biotechnology co. LTD (Beijing, China). This study was approved by the animal ethics committee of Institute of Medical Biology, Chinese Academy of Medical Science. All of the procedures were performed in accordance with relevant policies in China (Laboratory Animal Management Regulations).

\section{Nanoemulsion Formulations}

We used the self-emulsifying method, stirred the ingredients at low speed, and finally added water to milk. To select the proper formula with a high water dosage, the pseudo-ternary phase diagram was graphed according to the ratios of different components, and we prepared nanoemulsion adjuvant by adding the constituents as Tables $1-3$, except the aqueous phase, to obtain a total weight of $2 \mathrm{~g}$, followed by mixing with a magnetic stirrer (Wiggens, 
Table I Ratios of Various Components in Nanoemulsions AI-A4 (W\%)

\begin{tabular}{|l|l|l|l|l|l|l|}
\hline & Emulsifier I: Span 80 & Emulsifier2: Tween 80 & Co-Emulsifier: I,2-Propanediol & Oil Phase: White Oil & Water & Carrying Mode \\
\hline AI & $6.7 \%$ & $6.7 \%$ & $13.2 \%$ & $6.7 \%$ & $66.7 \%$ & Adsorption \\
A2 & $4.0 \%$ & $4.0 \%$ & $8.0 \%$ & $4.0 \%$ & $80 \%$ & Adsorption \\
A3 & $2.9 \%$ & $2.9 \%$ & $5.7 \%$ & $2.9 \%$ & $85.6 \%$ & Adsorption \\
A4 & $4.0 \%$ & $4.0 \%$ & $8.0 \%$ & $4.0 \%$ & $80 \%$ & Capsule \\
\hline
\end{tabular}

Table 2 Ratios of Various Components in Nanoemulsions DI-D4 (W\%)

\begin{tabular}{|l|l|l|l|l|l|l|}
\hline & EmulsifierI: Tween 20 & Emulsifier2: Span 80 & Co-Emulsifier: 1,2-Propanediol & Oil Phase: White Oil & Water & Carrying Mode \\
\hline DI & $6.7 \%$ & $6.7 \%$ & $13.3 \%$ & $6.7 \%$ & $66.7 \%$ & Adsorption \\
D2 & $4 \%$ & $4 \%$ & $8 \%$ & $4 \%$ & $80 \%$ & Adsorption \\
D3 & $2.9 \%$ & $2.9 \%$ & $5.7 \%$ & $2.9 \%$ & $85.6 \%$ & Adsorption \\
D4 & $4 \%$ & $4 \%$ & $8 \%$ & $4 \%$ & $80 \%$ & Capsule \\
\hline
\end{tabular}

Table 3 Ratios of Various Components in Nanoemulsion F, G, H, and I (W\%)

\begin{tabular}{|l|l|l|l|l|l|}
\hline NE & Emulsifier I:EL (W\%) & Emulsifier2:Span 80 & Co-Emulsifier: I,2-Propanediol & Oil Phase: Different Oil & Water \\
\hline F & $2.9 \%$ & $2.9 \%$ & $5.7 \%$ & White Oil:2.9\% & $85.6 \%$ \\
G & $2.9 \%$ & $2.9 \%$ & $5.7 \%$ & IPM:2.9\% & $85.6 \%$ \\
H & $2.9 \%$ & $2.9 \%$ & $5.8 \%$ & Soybean oil: $1.2 \%$ & $87.2 \%$ \\
I & $2.9 \%$ & $2.9 \%$ & $5.7 \%$ & Grape-kernel oil:2.9\% & $85.6 \%$ \\
\hline
\end{tabular}

Germany) at 700rpm for 5 min to form coarse emulsion. Water was added slowly (200 $\mu \mathrm{L}$ every 5 mins $)$, keep stirring until the system became clearer and transparent, this was the coarse emulsion. Then, speed to $500 \mu \mathrm{L} / \mathrm{min}$ until the setting concentration. The viscosity of the nanoemulsion decreased significantly, the color became lighter, and the transparency slightly decreased, but it would not break and delaminate even standing for a long time. Finally, the emulsion was filtered through membrane filters $(0.45 \mathrm{~mm})$ to remove coarse globules and debris.

Nanoemulsion preparation for different vaccine delivery modes was different in vaccine addition. Component ratio of A4 was completely the same as that of A2, including the antigen concentration. The difference between A4 and A2 concerned the process of water addition. Set A2, for example, here, normal saline (NS) was first added to an $80 \%$ concentration, and stirring was continued. Then, $290 \mu \mathrm{L}$ of inactivated $\mathrm{H} 3 \mathrm{~N} 2$ vaccine $(320 \mu \mathrm{g} / \mathrm{mL})$ was slowly added to make the total weight $10,290 \mu \mathrm{g}$, followed by mixing for 5 min. Thus, the antigen was uniformly distributed on the nanoemulsion surface, which we referred to as the adsorption mode. However, for A4, which we referred to as the capsule mode, the emulsion was prepared as follows: $290 \mu \mathrm{L}$ of inactivated $\mathrm{H} 3 \mathrm{~N} 2$ vaccine $(320 \mu \mathrm{g} / \mathrm{mL})$ was first added to form a coarse emulsion, after which NS was added dropwise to a certain concentration, and the antigen was thereby encapsulated inside the particles. Equal volume of Freund's adjuvant and vaccine solution were mixed and completely emulsified by syringe. Aluminium hydroxide, the original concentration $16.31 \mathrm{mg} / \mathrm{mL}$, was configured to $1 \mathrm{mg} / \mathrm{mL}$ when injected to animals.

\section{Adjuvant Characterization}

The particle size and PDI of the O/W emulsion were determined via dynamic light scattering (DLS) with a Zetasizer Nano-ZS 90 instrument (Malvern Instruments Corp, UK). In general, each emulsion sample was diluted 1:5000 with filtered distilled water and separated via ultrasonication at 50 watts before measurement at $25^{\circ} \mathrm{C}$. All the measurements were performed in duplicate.

The dynamic viscosity of the $\mathrm{O} / \mathrm{W}$ emulsion was measured at $25^{\circ} \mathrm{C}$ by simply aspirating $1 \mathrm{~mL}$ of the emulsion in a sucker. Then, the time at which $0.4 \mathrm{~mL}$ of the emulsion had flowed out was recorded. The $\mathrm{pH}$ value was tested with a $\mathrm{pH}$ meter, and all measurements were performed in triplicate.

The micro-structure and morphology of the nanoemulsion particles were observed with an H-7650 TEM (Hitachi LTD., Tokyo, Japan). Samples were diluted with PBS, and a few drops of glycerine were added, after which the 
samples were completely dispersed through the application of $50 \mathrm{~W}$ ultrasound for $5 \mathrm{~min}$. A $10 \mu$ laliquot of the sample was placed on the copper grid (400 mesh) surface, allowed to stand for 10 min to dry naturally, and finally stained with $2 \%$ phosphotungstic acid for $5 \mathrm{~min}$. Finally, the sample was observed under an appropriate magnification.

\section{Physical and Chemical Stability}

Nanoemulsion samples were stored at $4^{\circ} \mathrm{C}$, room temperature and $37^{\circ} \mathrm{C}$ for 3 months. Stability was analysed on the day of manufacture and after 2, 4, 6, 8, 10 and 12 weeks. The stability parameters included the $\mathrm{pH}$ value and particle size, also phase separation and agglomeration were observed by the naked eye after $10,000 \mathrm{r} / \mathrm{min}$ centrifugation. In addition, nanoemulsion's clarity was observed after sterilized by autoclaving at $115^{\circ} \mathrm{C}$ for $15 \mathrm{~min}$, to ensure stability.

Type identification was carried out by dyeing with methylene blue and Sudan red G. Two Schering bottles were filled with the nanoemulsion, and methylene blue or Sudan red $\mathrm{G}$ was then added along the bottle wall. The spreading process of the two dyestuffs was observed over $10 \mathrm{~min}$.

\section{Protein Release Assay}

To study the protein release rate, $4 \mathrm{~mL}$ of nanoemulsion containing $200 \mathrm{mg}$ of OVA was placed in a Dialysis bag and dialysis performed against $120 \mathrm{~mL}$ PBS. The dialysis appliance was placed in a $37{ }^{\circ} \mathrm{C}$ incubator. Fifty microliters dialysate were collected on $0.5,1,2,4,6,18,24,48$, $72 \mathrm{hr}$, and equivalent PBS was replaced in. OVA concentration was measured by Ultraviolet-visible spectrophotometer (DeNovix DS-11, DeNovix, USA).

\section{Immunization and Serum Collection}

Female ICR mice aged 6-8 weeks were provided by the Animal Experiment Centre of the Institute of Medical Biology, Chinese Academy of Medical Science. Mice (5 mice per group in the water concentration or different carrying mode tests, 8 mice per group in different oil phase tests) were immunized with the vaccine or with the vaccine mixed with NE via intramuscular injection in thigh gastrocnemius muscle (both legs, $200 \mu \mathrm{L}$ in each). Each mouse was injected with adjuvant + vaccine (Table 4 ). For the control group, mice were given NS, aluminium hydroxide adjuvant or CFA. All the mice were immunized at 0,1 and 3 weeks. Sera were collected at 1-9 weeks after the first immunization through the caudal vein and were then stored at $-20^{\circ} \mathrm{C}$.

\section{Immunogenicity Assessments}

To determine the haemagglutination-inhibition (HAI) titre, sera were treated with a receptor-destroying enzyme by

Table 4 Grouping Details of Nanoemulsion Adjuvant Immunized Mouse

\begin{tabular}{|c|c|c|c|c|}
\hline Group & Adjuvant & $\begin{array}{l}\text { Vaccine } \\
\text { Dosage }\end{array}$ & $\begin{array}{l}\text { Water } \\
\text { Concentration }\end{array}$ & $\begin{array}{l}\text { Carrying } \\
\text { Mode }\end{array}$ \\
\hline $\begin{array}{l}\text { Water concentration and Carrying mode animal } \\
\text { experiment }\end{array}$ & $\begin{array}{l}\text { Saline } \\
\text { None } \\
\mathrm{Al}(\mathrm{OH})_{3} \\
\mathrm{Al} \\
\mathrm{A} 2 \\
\mathrm{~A} 3 \\
\text { A4 } \\
\text { DI } \\
\text { D2 } \\
\text { D3 } \\
\text { D4 }\end{array}$ & $\begin{array}{l}\text { None } \\
1.8 \mu \mathrm{g} \\
1.8 \mu \mathrm{g} \\
1.8 \mu \mathrm{g} \\
1.8 \mu \mathrm{g} \\
1.8 \mu \mathrm{g} \\
1.8 \mu \mathrm{g} \\
1.8 \mu \mathrm{g} \\
1.8 \mu \mathrm{g} \\
1.8 \mu \mathrm{g} \\
1.8 \mu \mathrm{g}\end{array}$ & $\begin{array}{l}- \\
- \\
- \\
66.7 \% \\
80 \% \\
85.6 \% \\
80 \% \\
66.7 \% \\
80 \% \\
85.6 \% \\
80 \%\end{array}$ & $\begin{array}{l}- \\
- \\
- \\
\text { Adsorption } \\
\text { Adsorption } \\
\text { Adsorption } \\
\text { Capsule } \\
\text { Adsorption } \\
\text { Adsorption } \\
\text { Adsorption } \\
\text { Capsule }\end{array}$ \\
\hline $\begin{array}{l}\text { Oil phase } \\
\text { animal experiment }\end{array}$ & $\begin{array}{l}\text { Saline } \\
\text { None } \\
\text { CFA } \\
\text { F } \\
\text { G } \\
\text { H } \\
\text { I }\end{array}$ & $\begin{array}{l}\text { None } \\
0.9 \mu \mathrm{g} \\
0.9 \mu \mathrm{g} \\
0.9 \mu \mathrm{g} \\
0.9 \mu \mathrm{g} \\
0.9 \mu \mathrm{g} \\
0.9 \mu \mathrm{g}\end{array}$ & $\begin{array}{l}- \\
- \\
- \\
80 \% \\
80 \% \\
80 \% \\
80 \%\end{array}$ & $\begin{array}{l}\text { Adsorption } \\
\text { Adsorption } \\
\text { Adsorption } \\
\text { Adsorption } \\
\text { Adsorption } \\
\text { Adsorption } \\
\text { Adsorption }\end{array}$ \\
\hline
\end{tabular}


incubation overnight at $37^{\circ} \mathrm{C}$ to eliminate non-specific haemagglutination inhibitors, followed by heating at $56^{\circ} \mathrm{C}$ for $50 \mathrm{~min}$ to deactivate the receptor-destroying enzyme. Serum samples were serially (1:2) diluted using NS and mixed with $50 \mu \mathrm{L}$ of eight HA units of influenza virus, then incubated for $30 \mathrm{~min}$ at room temperature to neutralize the corresponding antibody. Finally, 1\% chicken red blood cells were added, and haemagglutination was observed. The HAI titres were defined as the highest serum dilution that completely inhibited haemagglutination.

Influenza virus-specific antibodies (IgG, IgG1, IgG2a, IFN- $\gamma$, IL-4) were quantified with a competitive inhibition enzyme-linked immunosorbent assay (ELISA) kit. Incubated plates were stored at $-20^{\circ}$ Cbefore opening when $10 \mu \mathrm{L}$ serum (all sera were collected at 5 weeks after first immunization) samples and $40 \mu \mathrm{L}$ of diluents were added to each test well. At the same time, $50 \mu \mathrm{L}$ of HRP-conjugated goat-anti-mouse IgG was added, followed by incubation for $1 \mathrm{~h}$ at $37^{\circ} \mathrm{C}$, and washing 5 times. For the chromogenic reaction, tetramethyl benzidine solution was added, followed by incubation at $37^{\circ} \mathrm{C}$ for $15 \mathrm{~min}$. The reaction was stopped by the addition of $0.1 \mathrm{~mL}$ of $2 \mathrm{M} \mathrm{H}_{2} \mathrm{SO}_{4}$. Finally, OD values were read at $450 \mathrm{~nm}$ within $15 \mathrm{~min}$.

\section{Safety Evaluation}

A preliminary experiment was performed before the real test. Mice were randomly grouped, with 20 mice in each group. After fasted for $12 \mathrm{~h}$, each mouse was given $0.25 \mathrm{~mL} / 10 \mathrm{~g} \mathrm{NE}$ via intraperitoneal injection, and the survival condition of the mice was observed for 30 days. Anatomical observations of the major organs (heart, liver, spleen, lung, kidney, etc.) were performed. If no death was observed under the maximum dosage, the maximal tolerance dose (MTD) was greater than $0.25 \mathrm{~mL} / 10 \mathrm{~g}$, and we judged the emulsions to show good safety. If there was any death of mice, the Karber method was used to test the LD50 and 95\% confidence limit for further evaluation.

\section{Statistical Analysis}

Arithmetic mean titres (AMT) were calculated to analyse antibody titres and HAI titres, which were used to draw a line chart. Each group was compared through descriptive statistical and repeated measures ANOVA. The significance level for evaluation of the research results was set at $\mathrm{p} \leq 0.05$.

\section{Results \\ Characterization of NE}

It can be seen that the initial NE was a transparent yellow liquid. After dilution, A and D became nearly colourless and semitransparent (Figure 1), the other NEs exhibited the same change when diluted. Under TEM viewing, the nanoparticles were nearly round in shape. Most of the A particles were approximately $40 \mathrm{~nm}$ and of uniform size. Most of the D particles were approximately $30 \mathrm{~nm}$ (Figure 2, Table 5). According to zetasizer measurements, the sizes of A1 to A3 ranged from $39 \mathrm{~nm}$ to $40 \mathrm{~nm}$, and the sizes of D1 to D3 ranged from $21 \mathrm{~nm}$ to $31 \mathrm{~nm}$, indicating that the particle size increased slightly with an increase in the water concentration, and particles in the whole nanoemulsion system tended to be more uniform. NEs such as G were nearly 40-50 nm. For G, the PDI was 0.109, indicating good uniformity and good stability. For other NEs, such as $\mathrm{H}$ and I, the particle
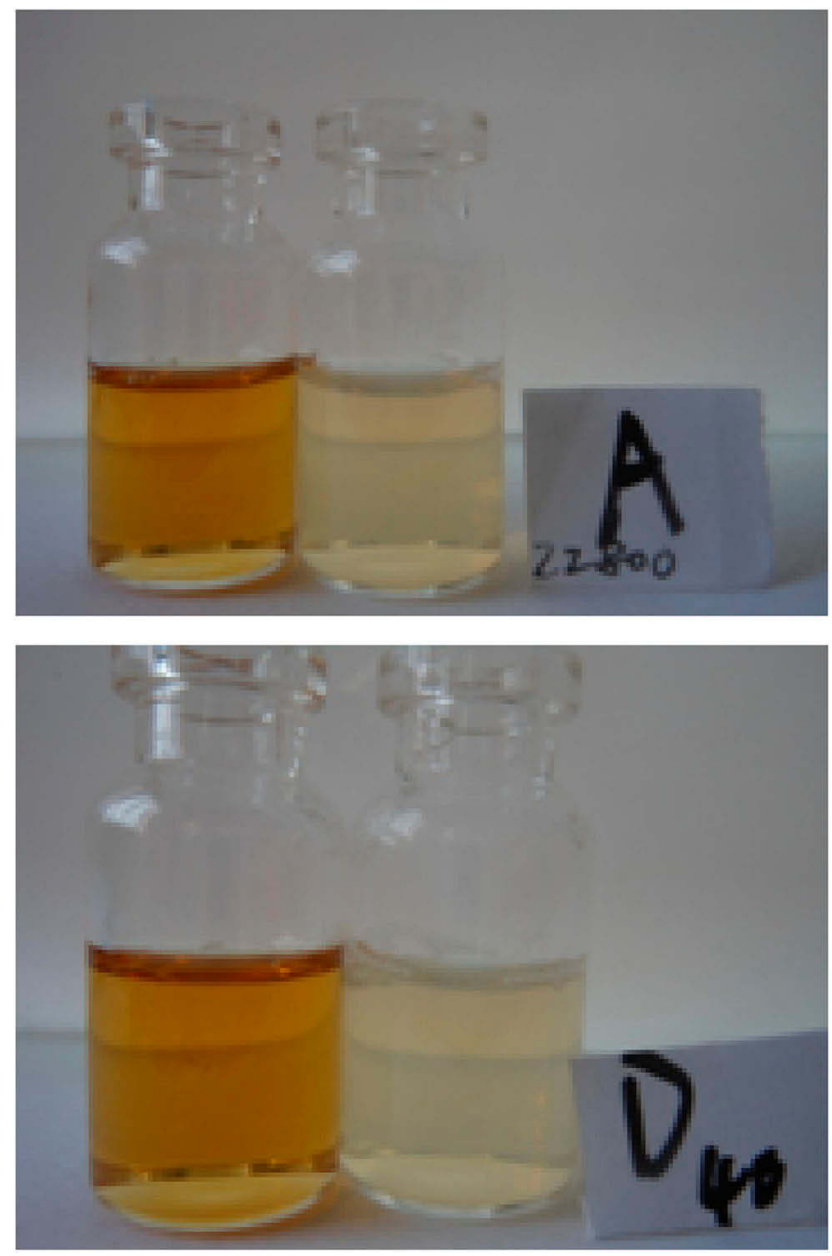

Figure I State of nanoemulsions A and D (The bottle showed a brownish-yellow color was the initially formed nanoemulsion, and the bottle showed a milky white color was nanoemulsion diluted with water to $80 \%$ ). 

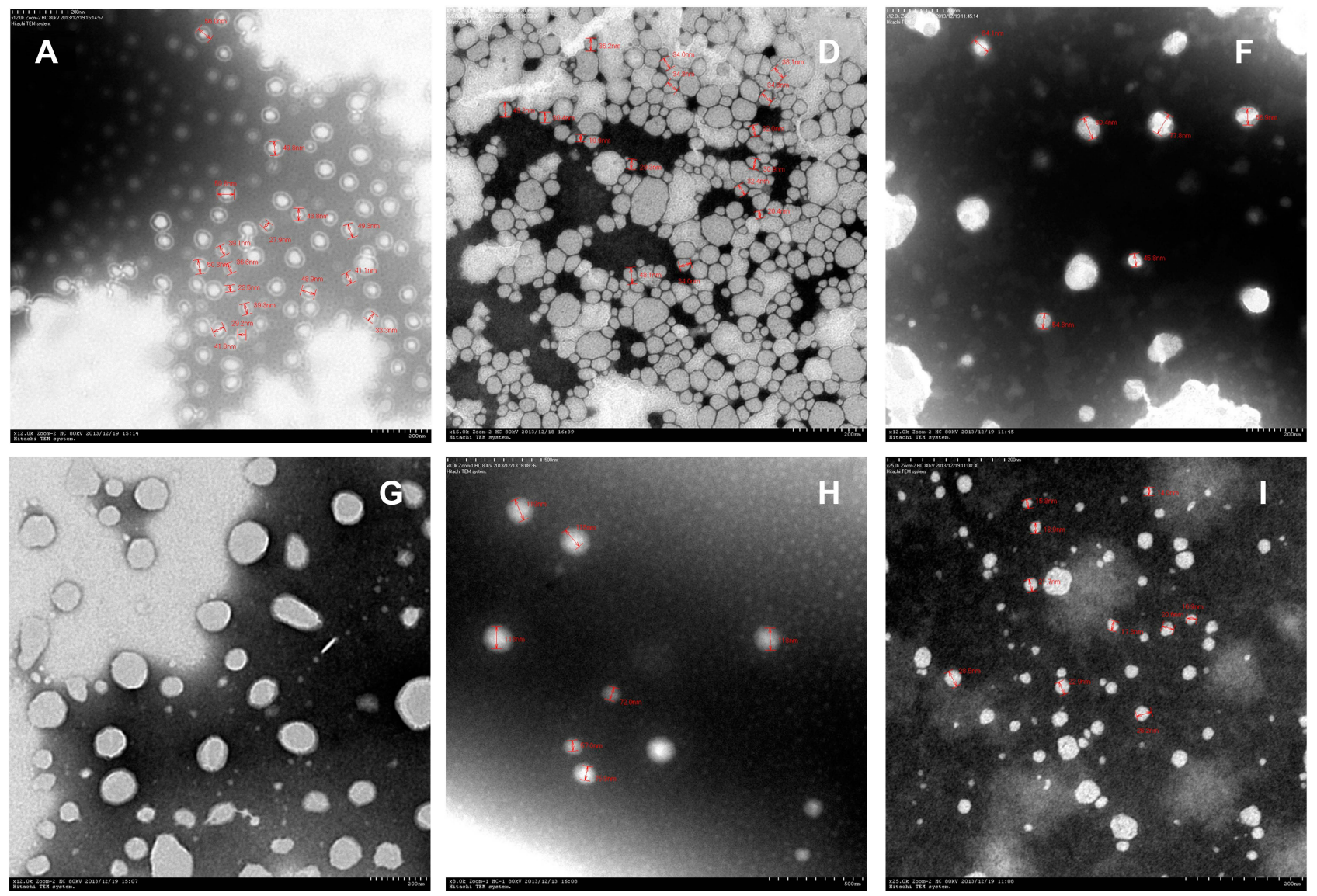

Figure 2 Electron microscopy of nanoemulsions (Each nanoemulsion sample was diluted with an appropriate amount of PBS, added with glycerin and ultrasonically dispersed, added to a copper mesh to be dried, and stained with phosphotungstate). Magnification: $(A \times 12,000 ; \mathrm{D} \times 15,000 ; \mathrm{F} \times 12,000 ; \mathrm{G} \times 12,000 ; \mathrm{H} \times 8000 ; 1 \times 25,000)$.

size was greater than $100 \mathrm{~nm}$, along with a greater PDI, and the particle density was less than A, D, and G.

\section{Stability of Nanoemulsions}

To investigate the stability of the NEs at different storage temperatures, the viscosity and $\mathrm{pH}$ were monitored under different storage conditions and sterilization processes. At $4^{\circ} \mathrm{C}$ and room temperature, the $\mathrm{pH}$ value and viscosity remained largely stable, and no stratification was observed during the 6-month period. At $37^{\circ} \mathrm{C}$, there were no changes

Table 5 Particles Size and Polydispersity Index of Nanoemulsions

\begin{tabular}{|l|l|l|l|l|l|}
\hline NE & $\begin{array}{l}\text { Particle Size } \\
(\mathbf{n m})\end{array}$ & PDI & NE & $\begin{array}{l}\text { Particle Size } \\
\text { (nm) }\end{array}$ & PDI \\
\hline AI & 39 & 0.170 & F & 175 & 0.320 \\
A2 & 40 & 0.169 & G & 51 & 0.109 \\
A3 & 40 & 0.168 & H & 173 & 0.404 \\
DI & 21 & 0.239 & I & 120 & 0.295 \\
D2 & 27. & 0.241 & & & \\
D3 & 31 & 0.178 & & & \\
\hline
\end{tabular}

in appearance or viscosity, but the $\mathrm{pH}$ value had slightly decreased by the end of the 6-month period (Table 6).

Upon autoclaving at $115^{\circ} \mathrm{C}$ for $15 \mathrm{~min}$, the properties of the emulsion adjuvant changed. The results showed that $\mathrm{A}$, $\mathrm{D}$ and I became cloudy, but could return to a uniform, transparent state after several days of standing. However, other NEs became cloudier. In addition, after the NEs were centrifuged for $30 \mathrm{~min}$ at a speed of $10000 \mathrm{r} / \mathrm{min}$, no delamination phenomenon of demulsification was observed (Table 7). The results showed that the nanoemulsions were stable and exhibited good resilience in practical use.

Overall, the physico-chemical stability data demonstrated good stability of the emulsion adjuvant, and autoclave sterilization can be performed before clinical application.

\section{Release Rate of Different Carrying Mode in Nanoemulsions A and D}

The capsule mode represented by A4 led the fastest protein release, with $100 \%$ protein released in $72 \mathrm{hrs}$, and the release rate became dramatically fast especially after $6 \mathrm{hrs}$, while the release of A2, D2, D4 in our $72 \mathrm{~h}$ test was significantly lower 
Table 6 Change in the $\mathrm{pH}$ of NEs

\begin{tabular}{|c|c|c|c|c|c|c|c|c|c|}
\hline \multirow[t]{2}{*}{ NE } & \multirow[t]{2}{*}{ Initial pH } & \multicolumn{3}{|c|}{6 Months pH } & \multirow[t]{2}{*}{ NE } & \multirow[t]{2}{*}{ Initial pH } & \multicolumn{3}{|c|}{6 Months pH } \\
\hline & & $4^{\circ} \mathrm{C}$ & RT & $37^{\circ} \mathrm{C}$ & & & $4^{\circ} \mathrm{C}$ & RT & $37^{\circ} \mathrm{C}$ \\
\hline Al & 6.54 & 6.54 & 6.54 & 6.26 & DI & 6.58 & 6.56 & 6.56 & 6.35 \\
\hline $\mathrm{A} 2$ & 6.54 & 6.54 & 6.54 & 6.26 & D2 & 6.58 & 6.58 & 6.56 & 6.48 \\
\hline $\mathrm{A} 3$ & 6.56 & 6.54 & 6.54 & 6.22 & D3 & 6.58 & 6.58 & 6.56 & 6.39 \\
\hline $\mathrm{F}$ & 6.46 & 6.46 & 6.35 & 6.38 & $\mathrm{H}$ & 6.36 & 6.45 & 6.45 & 6.40 \\
\hline G & 6.54 & 6.58 & 6.56 & 6.53 & I & 6.32 & 6.32 & 6.45 & 6.38 \\
\hline
\end{tabular}

Table 7 Clarity of NEs After Sterilization and Centrifugation

\begin{tabular}{|c|c|c|c|c|c|c|c|}
\hline NE & Initial & Sterilized & Centrifuged & NE & Initial & Sterilized & Centrifuged \\
\hline Al & +++++ & ++++ & +++++ & DI & +++++ & ++++ & +++++ \\
\hline $\mathrm{A} 2$ & ++++ & +++ & ++++ & D2 & ++++ & +++ & ++++ \\
\hline $\mathrm{A} 3$ & ++++ & +++ & ++++ & D3 & ++++ & +++ & ++++ \\
\hline $\mathrm{F}$ & +++++ & +++ & +++++ & $\mathrm{H}$ & ++++ & ++ & ++++ \\
\hline G & +++++ & +++ & +++++ & I & +++++ & +++ & +++++ \\
\hline
\end{tabular}

Notes: +++++ Indicates completely transparent; +++ Indicates semitransparent; + Indicates cloudy; ++++ Indicates status between +++++ and +++; ++ Indicates status between +++ and + , observed by naked eyes.

than A4, all less than $20 \%$, showing great control release. When compare D2 and D4, the two show a slight difference, D4 show gentle release initially and became quicker after $48 \mathrm{~h}$, finally reached $17 \%$ on $72 \mathrm{~h}$, slightly faster than D2 (Figure 3), overall, the adsorption mode showed a better control release effect than the capsule mode.

\section{HAI Response to Different Water Dosages and Carrying Modes}

To evaluate the immune response to the vaccine and different adjuvants, we tested HAI titres by haemagglutination inhibition. Repeated measures ANOVA was used to

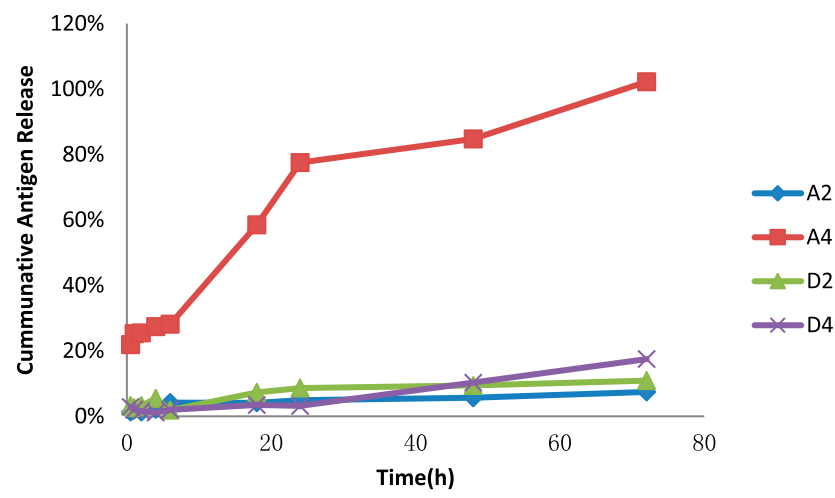

Figure 3 Release rate of nanoemulsions A and D. (A2 and D2 represented adsorption mode, and A4 and D4 represented capsule mode. Four-milliliter nanoemulsion contained $250 \mathrm{mg}$ OVA was wrapped in dialysis bag a, with $120 \mathrm{~mL}$ PBS as release medium, the dialysate was collected periodically for protein assay on $0.5, \mathrm{I}$, $2,4,6,18,24,48,72 \mathrm{hrs}$ ). compare HAI titres. The results showed that the HAI titre differed significantly as time changed $(\mathrm{F}=48.28, \mathrm{p}<0.05)$. The line chart (Figure 4A, Table 8) shows that all the mice reached the antibody titre peak at 28 or 35 days. Compared with the vaccine group, the NE adjuvant groups exhibited significantly higher titres over the entire test cycle, and A1 and $\mathrm{A} 2$ almost reached the same level as the aluminium hydroxide adjuvant group. Among these groups, A3 stimulated approximately 4 times the HAI antibody production as the single vaccine group, indicating that the three NE adjuvant groups showed a good adjuvant effect. For the D emulsion groups, all three emulsions contributed to higher production of HAI antibodies by the mice compared with the single vaccine group or aluminium hydroxide adjuvant group (Figure 4B, Table 9); the peak level was almost 2.5 times as high as in the aluminium hydroxide adjuvant group and 6 times as high as in the single vaccine group. Additionally, repeated measures ANOVA was used to compare the differences between various nanoemulsions and the control at different times, and the differences between the groups were statistically significant $(\mathrm{F}=10.91, \mathrm{p}<0.05)$. Overall, emulsion $\mathrm{D}$ performed better than $\mathrm{A}$ at the same time after immunization.

When different carrying modes were compared, the results became more complicated. For emulsion $\mathrm{A}$, the A4 group manifested a much lower antibody level than A2. Repeated measures analysis was used to compare the difference between A2 and A4 at different times. The 


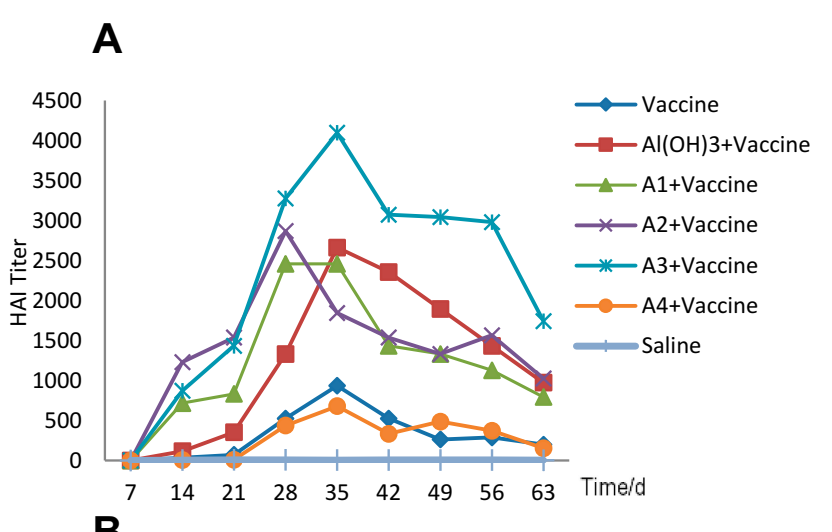

B

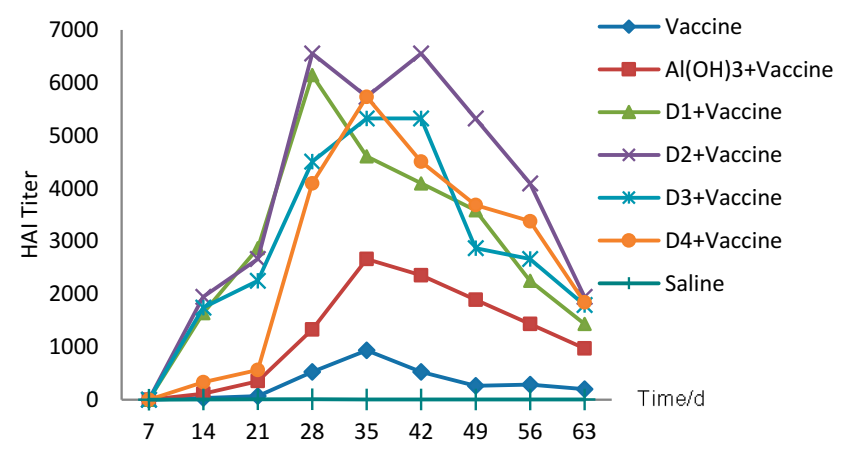

Figure $4 \mathrm{HAl}$ antibodies produced by different adjuvants with different water dosages or under different vaccine-carrying modes. (ICR mice were immunized with $1.8 \mu \mathrm{g}$ inactivated split-virus influenza vaccine mixed with $200 \mu \mathrm{L}$ adjuvant on days 0,7 , and 21 by intramuscular injection, and sera collected each week were tested by haemagglutination inhibition). The results are shown as the arithmetic mean endpoint, (A) showed nanoemulsion A prepared by different water concentration (AI, A2, A3) and different carrying modes (A2 and A4) each group contained 5 mice. And $(\mathbf{B})$ showed nanoemulsion $D$.

results showed that the differences were statistically significant $(\mathrm{F}=22.86, \mathrm{p}<0.05)$, almost the same as the single vaccine group $(\mathrm{F}=0.417, \mathrm{p}=0.536, \mathrm{p}>0.001)$ (Figure $4 \mathrm{~A}$, Table 8). However, for nanoemulsion $\mathrm{D}$, the $\mathrm{D} 4$ group showed an obviously worse adjuvant effect than D2 during the first 3 weeks after 3 weeks of stagnation, D4 unexpectedly produced 2 times the HAI antibodies compared to the aluminium hydroxide adjuvant group in the next 5 weeks (Figure 4B, Table 9), indicating its significant adjuvant effect. Repeated measures analysis showed that there was no obvious difference between D2 and D4 during this period $(\mathrm{F}=2.56, \mathrm{p}=0.148, \mathrm{p}>0.05)$.

Formula A's particle size remained constant when diluted (Table 5); its capsule effect was more intense. Therefore, the adsorption mode showed a far stronger adjuvant effect than the capsule mode within the body. In contrast, formula D's particle size increased gradually, and the antigens transferred from bound water to bulk water as dilution, and finally adsorb to the particle surface; therefore, its capsule mode also showed adjuvant effects. Generally, the adsorption mode was better than the capsule mode, and the following experiments were, therefore, all carried out in the adsorption carrying mode.

\section{Immune Responses to NEs with Different Water Dosages}

Influenza virus-specific antibodies (IgG, IgG1, IgG2a) were determined with ELISA kits showed that there were no significant differences between the A groups and the single vaccine group (Figure $5 \mathrm{~A}-\mathrm{C}$ ). However, the D2 groups showed significantly more $\operatorname{IgG}$ and $\operatorname{IgG} 2$ a than single vaccine group (Figure 5A and C: $\mathrm{F} 1=44.7, \mathrm{p}_{1}<0.05$; $\mathrm{F}_{2}=8.648, \mathrm{p}_{2}<0.05$ ), but no difference in IgG1 (Figure 4B: $\mathrm{F}=2.037, \mathrm{p}>0.05)$. The D3 groups showed significantly more IgG than single vaccine group (Figure $4 \mathrm{~A}$ and $\mathrm{C}$; $\mathrm{F}=1028.8, \mathrm{p}<0.05$;), but no difference in $\mathrm{IgG} 1$ and $\operatorname{IgG} 2 \mathrm{a}$ (Figure 5B and $\mathrm{C}$ ).

To further analyse immune types, IL-4 and IFN- $\gamma$ were detected via the ELISA method. The results showed that there were no differences between the single vaccine group and the D group (Figure 6A and B), which indicated that the NE adjuvant exhibited no relationship with cellular immunity; instead, the stimulation of the body's protection relied only on the humoral immunity to stimulate the body's protection.

Table 8 HAl Titer of Nanoemulsion A (Mean \pm SD)

\begin{tabular}{|c|c|c|c|c|c|c|c|c|c|}
\hline Group & 7 & 14 & 21 & 28 & 35 & 42 & 49 & 56 & 63 \\
\hline Saline & $0 \pm 0$ & $5 \pm 2$ & $8 \pm 5$ & $7 \pm 5$ & $5 \pm 2$ & $6 \pm 2$ & $6 \pm 5$ & $6 \pm 5$ & $4 \pm 0$ \\
\hline Vaccine & $0 \pm 0$ & $33 \pm 28$ & $70 \pm 53$ & $525 \pm 340$ & $934 \pm 535$ & $525 \pm 340$ & $262 \pm 170$ & $288 \pm 219$ & $198 \pm 195$ \\
\hline $\mathrm{Al}(\mathrm{OH})_{3}+$ vaccine & $0 \pm 0$ & $115 \pm 129$ & $352 \pm 290$ & $|33| \pm 687$ & $2662 \pm 3123$ & $2355 \pm 2220$ & $1894 \pm \mid 444$ & $|433 \pm 56|$ & $973 \pm 687$ \\
\hline Al+vaccine & $0 \pm 0$ & $717 \pm 280$ & $832 \pm 760$ & $2457 \pm 916$ & $2457 \pm 916$ & $|433 \pm 56|$ & $|33| \pm 687$ & $|I 26 \pm 56|$ & $794 \pm 262$ \\
\hline A2+vaccine & $0 \pm 0$ & $1228 \pm 776$ & $1536 \pm 724$ & $2867 \pm 1122$ & $1843 \pm 857$ & $1536 \pm 512$ & $|33| \pm|56|$ & $1564 . \pm 1437$ & $1024 \pm 57$ \\
\hline $\mathrm{A} 3+$ vaccine & $0 \pm 0$ & $870 \pm 715$ & $|433 \pm 56|$ & $3276 \pm 1122$ & $4096 \pm 2508$ & $3072 \pm 2896$ & $3042 \pm 2154$ & $2979 \pm 3239$ & $1740 \pm 1430$ \\
\hline A4+vaccine & $0 \pm 0$ & $5 \pm 2$ & $10 \pm 6$ & $437 \pm 537$ & $678 \pm 867$ & $332 \pm 245$ & $486 \pm 343$ & $372 \pm 415$ & $154 \pm 97$ \\
\hline
\end{tabular}


Table 9 HAI Titer of Nanoemulsion D (Mean \pm SD)

\begin{tabular}{|c|c|c|c|c|c|c|c|c|c|}
\hline Group & 7 & 14 & 21 & 28 & 35 & 42 & 49 & 56 & 63 \\
\hline Saline & $0 \pm 0$ & $5 \pm 2$ & $8 \pm 5$ & $7 \pm 5$ & $5 \pm 2$ & $6 \pm 2$ & $6 \pm 5$ & $6 \pm 5$ & $4 \pm 0$ \\
\hline Vaccine & $0 \pm 0$ & $33 \pm 28$ & $70 \pm 53$ & $525 \pm 340$ & $934 \pm 535$ & $525 \pm 340$ & $262 \pm 170$ & $288 \pm 219$ & $198 \pm 195$ \\
\hline $\mathrm{Al}(\mathrm{OH}) 3+$ Vaccine & $0 \pm 0$ & $115 \pm 129$ & $352 \pm 290$ & $|33| \pm 687$ & $2662 \pm 3123$ & $2355 \pm 2220$ & 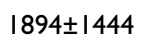 & $|433 \pm 56|$ & $973 \pm 687$ \\
\hline DI+Vaccine & $0 \pm 0$ & $|638 \pm 56|$ & $2867 \pm 1122$ & $6144 \pm 2896$ & $4608 \pm 3510$ & $4096 \pm 2508$ & $3584 \pm 1 \mid 45$ & $2252 \pm 1122$ & $|433 \pm 56|$ \\
\hline D2+Vaccine & $0 \pm 0$ & $1945 \pm 1374$ & $2662 \pm 1374$ & $6553 \pm 2243$ & $5734 \pm 2243$ & $6553 \pm 2243$ & $5324 \pm 2748$ & $4096 \pm 0$ & $1945 \pm 1275$ \\
\hline D3+Vaccine & $0 \pm 0$ & $1740 \pm 1430$ & $2252 \pm 1122$ & $4505 \pm 2243$ & $5324 \pm 2748$ & $5324 \pm 2748$ & $2867 \pm 1122$ & $2662 \pm 916$ & $1792 \pm 572$ \\
\hline D4+Vaccine & $0 \pm 0$ & $333 \pm 172$ & $563 \pm 280$ & $4096 \pm 2401$ & $5734 \pm 2243$ & $4506 \pm 2243$ & $3686 \pm 2670$ & $3379 \pm 3063$ & $1843 \pm 1384$ \\
\hline
\end{tabular}

\section{Immune Response to Different Oil Phases}

To explore the roles of different ingredients in the emulsions, different oils were tested to form relatively clear and transparent NEs. When the co-emulsifier and water phase exhibited the same composition and the same ratio (Table 3), the mice were immunized with F, G, H, and I, and HAI was detected in serum. The immunity test showed that the formula $(\mathrm{EL}=2.9 \%$; Span $80=2.9 \%$; $\mathrm{PEG}=5.4 \%$; oil $=2.9 \%$; water $=85.75 \%$ ) with $\mathrm{G}$ was much better at stimulating HAI antibody production than that with $\mathrm{F}$ (Figure 7, Table 10); ie, IPM was more effective than white oil in this formula. Moreover, $\mathrm{H}$ and $\mathrm{I}$, in which soybean oil or grape-kernel oil was used as the oil phase, had nearly no effect on the vaccine adjuvant. Generally, the adjuvant potential order was as follows: IPM $>$ white oil $>$ soybean oil >grape-kernel oil.

\section{Safety Evaluation}

To preliminary evaluate the safety of the emulsions, a maximum dose test was conducted. Mice were given $0.25 \mathrm{~mL} / 10 \mathrm{~g}$ of emulsions $\mathrm{A}, \mathrm{D}, \mathrm{F}, \mathrm{G}, \mathrm{H}$, and I. No reduction of activity or ingestion was observed, and no death appeared over the next 30 days after single intraperitoneal injection (Table 11). No obvious histologic changes were found in the heart, liver, spleen, lung or kidney. The MTD roughly proved that these nanoemulsions have the potential to be applied to the body.

\section{Discussion}

Water is the main ingredient of nanoemulsions, and it may play two different roles in the formulation of a nanoemulsion. Some portion of the water exists in the surroundings of the oil phase as the bound water, while the excess water exists around the nanoparticle as a continuous phase, namely bulk water, which plays a diluent role. ${ }^{23}$ Our research showed that adding water diluted the nanoparticles in formula $\mathrm{A}$, which was an $\mathrm{O} / \mathrm{W}$ type emulsion, and may decrease the particle density. The difference in the intensity of the immune response induced by different amounts of water is probably due to the differences in the density of nanoparticles. ${ }^{2,4}$ Because nanoparticles form stable nanoemulsion particles before water dilution, the subsequently added antigen mainly exists in the bulk water, and can, therefore, be freely transported and adsorbed on the surface of nanoparticles, which
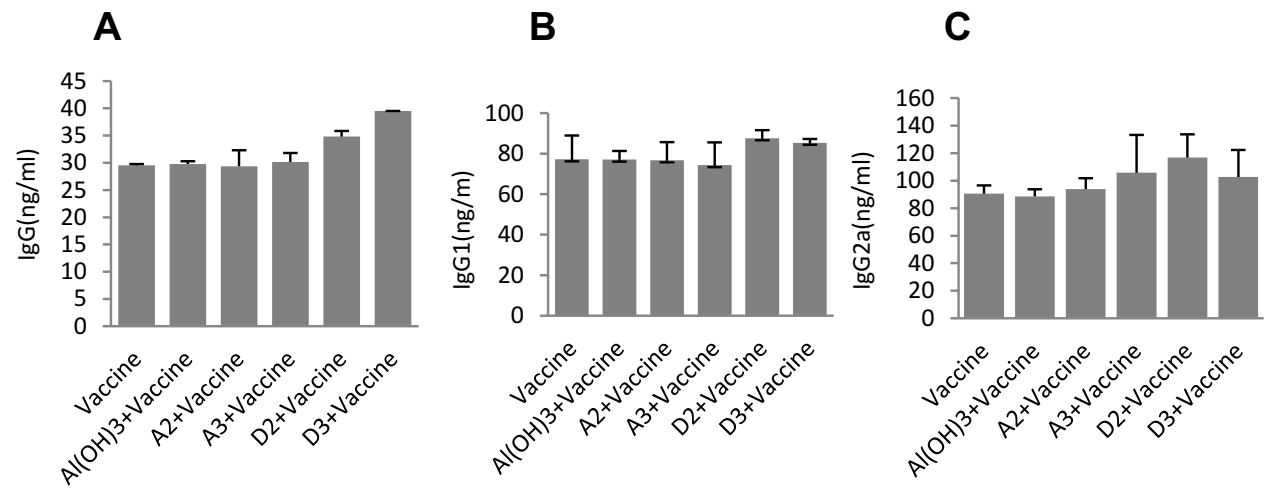

Figure 5 Effect of adjuvant formulations on humoral immune responses induced by different adjuvants. (ICR mice were immunized with I.8 $\mu$ inactivated split-virus influenza vaccine mixed with $200 \mu \mathrm{L}$ adjuvant on days 0,7 , and 21 by intramuscular injection). Antigen-specific lgG (A), IgG (B) and IgG2a (C) were determined by indirect ELISA. The serum 35 days after fist immunization was added as a primary antibody to the empty plate (has been coated with the capture antigen, and HRP-labeled human anti-mouse $\lg G$, $\lg G I, \lg G 2 a$ as secondary antibodies). The results were shown as the arithmetic mean, $n=5$ per group. 
A

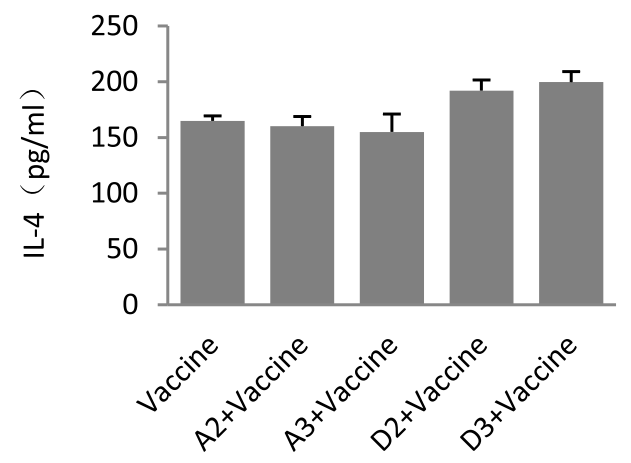

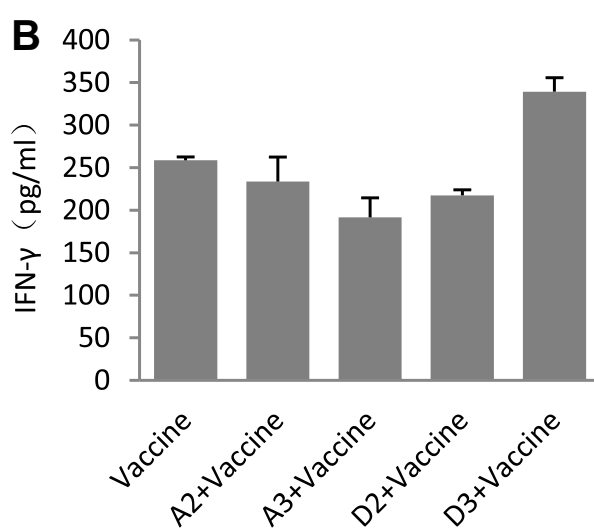

Figure 6 Cellular immune response induced by different adjuvants. ICR mice were immunized with the inactivated split-virus influenza vaccine mixed with adjuvant.(ICR mice were immunized with I. $8 \mu$ g inactivated split-virus influenza vaccine mixed with $200 \mu \mathrm{L}$ adjuvant on days 0,7 , and 2 I by intramuscular injection. The serum 35 days after fist immunization was detected, IL-4 (A)) and IFN- $\gamma(\mathbf{B})$ were determined by indirect ELISA. The results were shown as the arithmetic mean, $\mathrm{n}=5$ per group.

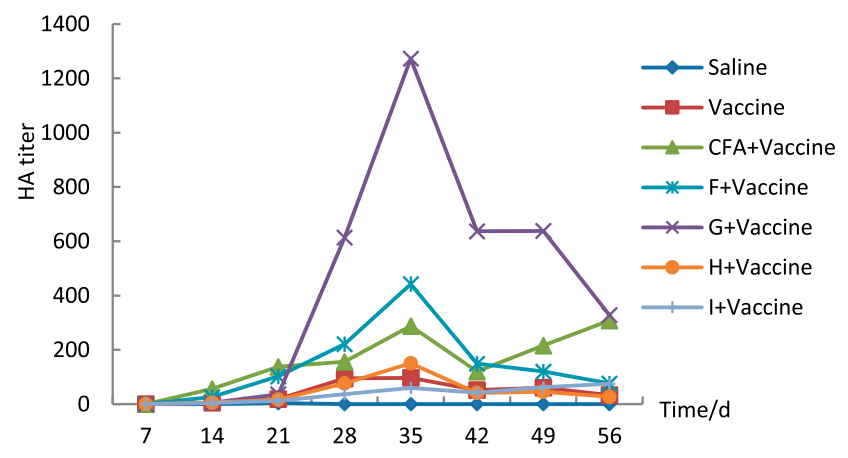

Figure $7 \mathrm{HAl}$ antibodies produced by different oil phases (Tween 80=2.9\%; Span $80=2.9 \%$; PEG=5.4\%; oil=2.9\%; water=85.75\%). Mice were immunized with $0.9 \mu$ g. Inactivated $\mathrm{H} 3 \mathrm{~N} 2$ split-virus influenza vaccine was mixed with $200 \mu \mathrm{L}$ adjuvant on days 0,7 , and 21 by intramuscular injection, and sera collected each week were tested by haemagglutination inhibition. And sera were tested by Haemagglutination inhibition. The results were shown as the arithmetic mean, $n=8$ per group.

can easily be identified by antigen-presenting cells, thus helping to stimulate antibody production. ${ }^{25,26}$ In the capsule mode, however, the antigen solution is firstly added to form a coarse emulsion. And finally, be exposed to the bulk water and never adsorbed to the nanoparticle surface, so it causes nearly the same level of the immune response as none adjuvant group. Thus, nanoemulsions should have a proper particle density to optimize their adjuvant effect; for different formulas, the optimal water concentration can be different. ${ }^{27}$ Another point is that hydrated ions formed in nanoemulsion system play a significant role in interaction between droplet and hydrophilic substance, which decide the adsorption rate of protein. Importantly, hydrated ions yield increases and its lifetime decreases with the increase of water content, ${ }^{28}$ so we suppose that the water concentration that affects adsorption rate might be because of hydrated ions, and finally affect antigen presentation and immune response.

Additionally, $\mathrm{pH}$ has a major impact on the physical stability of the emulsions, causing droplet aggregation at $\mathrm{Ph}$ 4-5, and the alkaline environment is conducive to stabilize the nanoemulsion droplets, ${ }^{29,30}$ since the $\mathrm{pH}$ value and body liquids complex in intracorporeal environment, stability of the nanoemulsions directly affects its stability and antigen releasing, even its immune enhancement.

Emulsifiers and oil play a major role in the formation of nanoemulsions and mainly decide their physicochemical properties. With an increase in the emulsifier concentration, the particle size, polydispersity index and the surface tension decrease, and the surface area of the droplets increases. Particle size depends mainly on the proportion of surfactants and oil. A high concentration of surfactants can cause the oil

Table 10 HAl Titer of Different Oil Phase Nanoemulsion (Mean \pm SD)

\begin{tabular}{|c|c|c|c|c|c|c|c|c|}
\hline Group & 7 & 14 & 21 & 28 & 35 & 42 & 49 & 56 \\
\hline NS & $0 \pm 0$ & $0 \pm 0$ & $4 \pm 0$ & $0 \pm 0$ & $0 \pm 0$ & $0 \pm 0$ & $0 \pm 0$ & $0 \pm 0$ \\
\hline Vaccine & $0 \pm 0$ & $6 \pm 1$ & $18 \pm 7$ & $94 \pm 25$ & $97 \pm 25$ & $52 \pm 12$ & $61 \pm 13$ & $34 \pm 8$ \\
\hline CFA+Vaccine & $0 \pm 0$ & $56 \pm 16$ & $138 \pm 28$ & $156 \pm 22$ & $288 \pm 40$ & $120 \pm 16$ & $216 \pm 52$ & $308 \pm 120$ \\
\hline $\mathrm{F}+\mathrm{Vaccine}$ & $0 \pm 0$ & $26 \pm 6$ & $|03 \pm 2|$ & $221 \pm 50$ & $442 \pm 78$ & $149 \pm 25$ & $120 \pm 18$ & $76 \pm 12$ \\
\hline G+Vaccine & $0 \pm 0$ & $5 \pm 1$ & $36 \pm 7$ & $614 \pm 263$ & $|273 \pm 70|$ & $637 \pm 350$ & $638 \pm 350$ & $328 \pm 175$ \\
\hline $\mathrm{H}+\mathrm{Vaccine}$ & $0 \pm 0$ & $6 \pm 1$ & $17 \pm 5$ & $77 \pm 44$ & $|5| \pm 88$ & $42 \pm 22$ & $46 \pm 21$ & $27 \pm 10$ \\
\hline I+Vaccine & $0 \pm 0$ & $4 \pm 0$ & $12 \pm 5$ & $37 \pm 12$ & $60 \pm 23$ & $42 \pm 13$ & $62 \pm 21$ & $75 \pm 15$ \\
\hline
\end{tabular}


Table I I Maximum Tolerated Dose of Each Formulation

\begin{tabular}{|l|l|l|l|}
\hline NE & Safety Evaluation & NE & Safety Evaluation \\
\hline A & MTD $>0.25 \mathrm{~mL} / 10 \mathrm{~g}$ & G & MTD $>0.25 \mathrm{~mL} / 10 \mathrm{~g}$ \\
D & MTD $>0.25 \mathrm{~mL} / 10 \mathrm{~g}$ & H & MTD $>0.25 \mathrm{~mL} / 10 \mathrm{~g}$ \\
F & MTD $>0.25 \mathrm{~mL} / 10 \mathrm{~g}$ & I & MTD $>0.25 \mathrm{~mL} / 10 \mathrm{~g}$ \\
\hline
\end{tabular}

phase at the emulsion phase inversion point to undergo complete solubilization, which will increase the likelihood of forming small particles. In contrast, low concentration of surfactant cannot cause the oil phase to undergo complete solubilization, thus resulting in the formation of larger emulsion droplets. ${ }^{29}$ Only when surfactants and oil reach a certain proportion can layered structure be formed at the phase transition point, which also determines other physicochemical properties, such as stability, and the polydispersity index, thus greatly affecting the adjuvant effect. ${ }^{30}$ Herein, we have placed a strong emphasis on the study of the oil phase, and the results showed that IPM was the most efficient oil phase.

In order to explore the reasons in depth, particle size and the polydispersity index are considered as associated factors of the adjuvant effect. ${ }^{31,32}$ Kanchan and Panda found that $200-600 \mathrm{~nm}$ particles can be easily recognized by lymph node antigen-presenting cells (APCs), causing Th1-type cellular immunity, and $2-8 \mu \mathrm{m}$ particles are presented via macrophage phagocytosis or pinocytosis to the lymph nodes, stimulating humoral immunity. ${ }^{33}$ Oyewumi proposed $500 \mathrm{~nm}$ as a watershed because particles larger than $500 \mathrm{~nm}$ and those smaller than $500 \mathrm{~nm}$ stimulate different immune responses. ${ }^{34} \mathrm{AF} 03$ and AF04, which are produced by Sanofi Pasteur, exhibit a particle size of less than $100 \mathrm{~nm}$ and can act synergistically to augment specific antibody and Th-1 cellular immune responses in mice. ${ }^{35}$ In fact, it is difficult to pinpoint the upper limit of particle size in relation to the adjuvant effect because a nanoemulsion is not an absolutely uniform system in terms of particle size. ${ }^{36}$ Instead, the effective particle size is within a certain range, and particles in this range are easier for the immune system to identify and present. A nanoemulsion system with an appropriate particle size and effective particle uniformity guarantees the stimulation of a strong immune response. So, as it can be seen from Figure 6 and Table 5, the nanoemulsion $\mathrm{G}$ involved in IPM has a much better adjuvant effect than other formulations, and it also has smaller particle size and the most uniform particles.

Additionally, appropriate interfacial membrane strength and mutual repulsion between emulsion drops are the main reasons for emulsion stability. ${ }^{37}$ Some studies suggest that when the size distribution of nanoparticles is not uniform, particles with a large difference in volume tend to collide; thus, small particles can easily merge with large particles. ${ }^{38}$ Therefore, the polydispersity index is another important factor for judging stability and adjuvant effectiveness. ${ }^{39}$ Herein, our research also showed that emulsions $\mathrm{H}$ and I, with a larger PDI, had no adjuvant effect. In a nutshell, emulsions with a smaller size and uniformly dispersed particles exert a better adjuvant effect than those with larger particles and large differences in size.

The effect of mode of carrying on the effects of adjuvants is also considered in this research. Adjuvant effects for different formulations vary depending on the mode of carrying. The adsorption mode showed a better control release effect than the capsule mode in the protein release assay, when associated with its adjuvant effect, A4 stimulated the lowest serum antibody, which was close to the vaccine group, while A2, D2, and D4 all showed strong adjuvant effects. Immunostimulation of nanoemulsions was related to protein release, ${ }^{40}$ which is consistent with the results reported in many works of literature. It is contrary to our previous conjectures that the nanoemulsion particle wraps the protein if the protein solution is directly added as the water phase to form the coarse nanoemulsion, the result turns out that capsule mode (namely protein is added first) accelerates its release, and the adsorption mode is unexpectedly conducive to slow release of the vaccine and showed an ideal adjuvant effect. However, the reason why the different sequence of vaccine additions leads to completely different protein release and finally cause different immune effect is still uncertain. Generally, the adsorption mode was better than the capsule mode as an adjuvant.

More in-depth and comprehensive research will focus on the antigen dose sparing and immunoprotective properties, we plan to perform challenge studies and other immune response factors research to further explain adjuvant mechanism of nanoemulsion.

Safety is also an important factor in clinical use. The toxicity of a formula comes mainly from non-ionic surfactants such as EL and IPM. EL can readily cause allergic reactions, and IPM is also toxic. ${ }^{41,42}$ Therefore, choosing biosafe components is also a key aspect to consider in our future research. Chickens and pigs will be considered as animal models in our upcoming research for further study of nanoemulsion safety, to explore the immuno-enhancing effects of nanoemulsion adjuvants in the prevention of avian and swine flu before clinical use. 


\section{Acknowledgments}

This research is supported by Natural Science Foundation of Hunan Province (2019JJ50508), the Innovation Team of Yunnan Province, the CAMS Innovation Fund for Medical Sciences (CIFMS:2016-I2M-3-026), Medical Science and Technology Innovation Project of Chinese Academy of Medical Sciences (Grant No. 2016-I2M-1-019). The Scientific Research Fund of Hunan Provincial Education Department (17C1383), and the project of the Science and Technology Bureau of Hengyang City (2016KJ67).

\section{Disclosure}

The authors report no conflicts of interest in this work.

\section{References}

1. Lowe L, Dopson SA, Budd AP. Pandemic Influenza readiness report on laboratory and epidemiology capacity-United states and territories 2015. Health Secur. 2018;16(4):239-243. doi:10.1089/ hs.2018.0021

2. Caini S, Kroneman M, Wiegers T, et al. Clinical characteristics and severity of influenza infections by virus type, subtype, and lineage: a systematic literature review. Influenza Other Respir Viruses. 2018;12:780-792. doi:10.1111/irv.12575

3. Kwetkat A, Leischker A, Heppner HJ. Influenza: special aspects in old age.Z. Gerontol Geriatr. 2018;51:585-596. doi:10.1007/s00391-0181418-4

4. Tregoning JS, Russell RF, Kinnear E. Adjuvanted influenza vaccines. Hum Vaccin Immunother. 2018;14:550-564. doi:10.1080/216455 15.2017.1415684

5. Stowe J, Andrews N, Kosky C, et al. Risk of narcolepsy after AS03 adjuvanted pandemic A/H1N1 2009 influenza vaccine in adults: a case-coverage study in England. Sleep. 2016;39:1051-1057. doi: $10.5665 /$ sleep .5752

6. Pellegrino P, Clementi E, Radice S. On vaccine's adjuvants and autoimmunity: current evidence and future perspectives. Autoimmun Rev. 2015;14:880-888. doi:10.1016/j.autrev.2015.05. 014

7. Fox A, Quinn KM, Subbarao K. Extending the breadth of influenza vaccines: status and prospects for a universal vaccine. Drugs. 2018;78:1297-1308. doi:10.1007/s40265-018-0958-7

8. Vesikari T, Kirstein J, Go G D, et al. Efficacy, immunogenicity, and safety evaluation of an MF59-adjuvanted quadrivalent influenza virus vaccine compared with non-adjuvanted influenza vaccine in children: a multicentre, randomised controlled, observer-blinded, Phase 3 trial. Lancet Respir Med. 2018;5(6):345-356. doi:10.1016/S2213-2600(18) 30108-5

9. van der Most RG, Clément F, Willekens J, et al. Long-term persistence of cell-mediated and humoral responses to $\mathrm{A}(\mathrm{H} 1 \mathrm{~N} 1)$ pdm09 influenza virus vaccines and the role of the AS03 adjuvant system in adults during two randomized controlled trials. Clin Vaccine Immunol. 2017;24:pii: e00553-e00516. doi:10.1128/ CVI.00553-16

10. Wilkins AL, Kazmin D, Napolitani G, et al. AS03- and MF59-adjuvanted influenza vaccines in children. Front Immunol. 2017;13:1760. doi:10.3389/fimmu.2017.01760

11. Sarkanen TO, Alakuijala APE, Dauvilliers YA, Partinen MM. Incidence of narcolepsy after H1N1 influenza and vaccinations: systematic review and meta-analysis. Sleep Med Rev. 2018;4:177-186. doi:10.1016/j.smrv.2017.06.006
12. Persson I, Granath F, Askling J, et al. Risks of neurological and immune-related diseases, including narcolepsy, after vaccination with Pandemrix: a population- and registry-based cohort study with over 2 years of follow-up. J Intern Med. 2017;281:102-104. doi:10.1111/joim. 12581

13. Wei Y, Xiong J, Larson NR, et al. Effect of 2 emulsion-based adjuvants on the structure and thermal stability of staphylococcus aureus alpha-toxin. J Pharm Sci. 2018;107:2325-2334. doi:10.1016/j. xphs.2018.05.019

14. Abbasi S, Kajimoto K, Harashima H. Elimination of the biphasic pharmacodynamics of $15 \mathrm{~d}-\mathrm{PGJ} 2$ by controlling its release from a nanoemulsion. Int J Nanomedicine. 2016;11:2685-2694. doi:10.21 47/IJN.S106297

15. Del Giudice G, Rappuoli R, Didierlaurent AM. Correlates of adjuvanticity: a review on adjuvants in licensed vaccines. Semin Immunol. 2018;39:14-21. doi:10.1016/j.smim.2018.05.001

16. Saha A, John VT, Bose A. In situ assembly of hydrophilic and hydrophobic nanoparticles at oil-water interfaces as a versatile strategy to form stable emulsions. ACS Appl Mater Interfaces. 2015;7:21010-21014. doi:10.1021/acsami.5b06940

17. Yamala AK, Nadella V, Mastai Y, Prakash H, Paik P. Poly$\mathrm{N}$-acryloyl-(l-phenylalanine methyl ester) hollow core nanocapsules facilitate sustained delivery of immunomodulatory drugs and exhibit adjuvant properties. Nanoscale. 2017;9:14006-14014. doi:10.1039/ c7nr03724d

18. Deng J, Cai W, Jin F. A novel oil-in-water emulsion as a potential adjuvant for influenza vaccine: development, characterization, stability and in vivo evaluation. Int $J$ Pharm. 2014;468:187-195. doi:10.1016/j.ijpharm.2014.04.003

19. O'Hagan DT, Fox CB. New generation adjuvants-from empiricism to rational design. Vaccine. 2015;33:B14-B20. doi:10.1016/j. vaccine.2015.01.088

20. Jakob V, Brunner L, Barnier-Quer C, et al. Accounting for adjuvant-induced artifacts in the characterization of vaccine formulations by polyacrylamide gel electrophoresis. Ther Adv Vaccin. 2017;5:31-38. doi:10.1177/2051013617702072

21. Fox CB, Baldwin SL, Duthie MS, Reed SG, Vedvick TS. Immunomodulatory and physical effects of oil composition in vaccine adjuvant emulsions. Vaccine. 2011;29:9563-9572. doi:10.1016/j. vaccine.2011.08.089

22. Wong PT, Leroueil PR, Smith DM, et al. Formulation, high throughput in vitro screening and in vivo functional characterization of nanoemulsion-based intranasal vaccine adjuvants. PLoS One. 2015;10:e0126120. doi:10.1371/journal.pone.0126120

23. Hensel JK, Carpenter AP, Ciszewski RK, et al. Molecular characterization of water and surfactant AOT at nanoemulsion surfaces. Proc Natl Acad Sci USA. 2017;114:13351-13356. doi:10.1073/pnas.170 0099114

24. Xia Y, Wu J, Wei W, et al. Exploiting the pliability and lateral mobility of Pickering emulsion for enhanced vaccination. Nat Mater. 2018;17:187-194. doi:10.1038/nmat5057

25. Vemireddy S, Pallavi P, Halmuthur MSK. Chitosan stabilized nasal emulsion delivery system for effective humoral and cellular response against recombinant tetravalent dengue antigen. Carbohydr Polym. 2018;190:129-138. doi:10.1016/j.carbpol.2018.02.073

26. Huang $\mathrm{CH}$, Huang $\mathrm{CY}$, Huang $\mathrm{MH}$. Unsaturated squalene content in emulsion vaccine adjuvants plays a crucial role in ROS-mediated antigen uptake and cellular immunity. Mol Pharm. 2018;15:420-429. doi:10.1021/acs.molpharmaceut.7b00800

27. Rose F, Wern JE, Ingvarsson PT, et al. Engineering of a novel adjuvant based on lipid-polymer hybrid nanoparticles: a quality-bydesign approach. J Control Release. 2015;210:48-57. doi:10.1016/j. jconrel.2015.05.004

28. André P, Ninham BW, Pileni MP. Supra-aggregates. Adv Colloid Interface Sci. 2001;89-90:155-167. doi:10.1016/s0001-8686(00) 00051-8 
29. Fox CB, Lin S, Sivananthan SJ, et al. Effects of emulsifier concentration, composition, and order of addition in squalene-phosphatidylcholine oil-in-water emulsions. Pharm Dev Technol. 2011;16:511-519. doi:10.3109/10837450.2010.495397

30. Najafi-Taher R, Ghaemi B, Amani A. Delivery of adapalene using a novel topical gel based on tea tree oil nano-emulsion: permeation, antibacterial and safety assessments. Eur J Pharm Sci. 2018;120:142. doi:10.1016/j.ejps.2018.04.029

31. Shah RR, O'Hagan DT, Amiji MM, Brito LA. The impact of size on particulate vaccine adjuvants. Nanomedicine (Lond). 2014;9:2671-2681. doi:10.2217/nnm.14.193

32. Okada T, Koide T. Uniform-sized silica nanocapsules produced by addition of salts to a water-in-oil emulsion template. Langmuir. 2018;34:9500-9506. doi:10.1021/acs.langmuir.8b01490

33. Kanchan V, Katare YK, Panda AK. Memory antibody response from antigen loaded polymer particles and the effect of antigen release kinetics. Biomaterials. 2009;30:4763-4776. doi:10.1016/j.biomaterials.2009.05. 075

34. Oyewumi MO, Kumar A, Cui Z. Nano-microparticles as immune adjuvants: correlating particle sizes and the resultant immune responses. Expert Rev Vaccin. 2010;9:1095-1107. doi:10.1586/erv.10.89

35. Haensler J, Probeck P, Su J, et al. Design and preclinical characterization of a novel vaccine adjuvant formulation consisting of a synthetic TLR4 agonist in a thermoreversible squalene emulsion. Int J Pharm. 2015;486:99-111. doi:10.1016/j.ijpharm.2015.03.028

36. Jia C, Yang T, Liu Y, et al. A novel human papillomavirus 16 L1 pentamer-loaded hybrid particles vaccine system: influence of size on immune responses. ACS Appl Mater Interfaces. 2018;10 (42):35745-35759. doi:10.1021/acsami.8b11556
37. Rauta PR, Nayak B. Parenteral immunization of PLA/PLGA nanoparticle encapsulating outer membrane protein (Omp) from Aeromonas hydrophila: evaluation of immunostimulatory action in Labeo rohita (rohu). Fish Shellfish Immunol. 2015;44:287-294. doi:10.1016/j.fsi.2015.02.007

38. Whitby CP, Bahuon F. Droplet fusion in oil-in-water pickering emulsions. Front Chem. 2018;6:213. doi:10.3389/fchem.2018.00213

39. Md S, Kuldeep Singh JKA, Waqas M, et al. Nanoencapsulation of betamethasone valerate using high pressure homogenization-solvent evaporation technique: optimisation of formulation and process parameters for efficient dermal targeting. Drug Dev Ind Pharm. 2018;8:1-32. doi:10.1080/03639045.2018.1542704

40. Yang Y, Chen L, Sun HW, et al. Epitope-loaded nanoemulsion delivery system with ability of extending antigen release elicits potent Th1 response for intranasal vaccine against helicobacter pylori. J Nanobiotechnol. 2019;17. doi:10.1186/s12951-019-0441-y

41. Naseef MA, Ibrahim HK, Nour SAE. Solid form of lipid-based self-nanoemulsifying drug delivery systems for minimization of diacerein adverse effects: development and bioequivalence evaluation in albino rabbits. AAPS Pharm Sci Tech. 2018;19:3097-3109. doi:10.1208/s12249-018-1138-5

42. Akram MR, Ahmad M, Abrar A, Sarfraz RM, Mahmood A. Formulation design and development of matrix diffusion controlled transdermal drug delivery of glimepiride. Drug Des Devel Ther. 2018;21:349-364. doi:10.2147/DDDT.S147082
International Journal of Nanomedicine

\section{Publish your work in this journal}

The International Journal of Nanomedicine is an international, peerreviewed journal focusing on the application of nanotechnology in diagnostics, therapeutics, and drug delivery systems throughout the biomedical field. This journal is indexed on PubMed Central, MedLine, CAS, SciSearch ${ }^{\circledR}$, Current Contents ${ }^{\mathbb{R}} /$ Clinical Medicine,
Journal Citation Reports/Science Edition, EMBase, Scopus and the Elsevier Bibliographic databases. The manuscript management system is completely online and includes a very quick and fair peer-review system, which is all easy to use. Visit http://www.dovepress.com/ testimonials.php to read real quotes from published authors. 